\title{
BMJ Global Health Mental health conditions after snakebite: a scoping review
}

\author{
Soumyadeep Bhaumik (D) , ${ }^{1,2}$ Sudha Kallakuri, ${ }^{2,3}$ Amanpreet Kaur, ${ }^{1}$ \\ Siddhardha Devarapalli, ${ }^{3}$ Mercian Daniel $^{1}$
}

To cite: Bhaumik S, Kallakuri S, Kaur A, et al. Mental health conditions after snakebite: a scoping review. BMJ Global Health 2020;5:e004131. doi:10.1136/ bmjgh-2020-004131

Handling editor Soumitra S Bhuyan

SB and SK contributed equally.

Received 7 October 2020

Revised 8 November 2020

Accepted 11 November 2020

Check for updates

(C) Author(s) (or their employer(s)) 2020. Re-use permitted under CC BY-NC. No commercial re-use. See rights and permissions. Published by BMJ

${ }^{1}$ The George Institute for Global Health, New Delhi, India

${ }^{2}$ The George Institute for Global Health, Faculty of Medicine, University of New South Wales, Sydney, New South Wales, Australia

${ }^{3}$ The George Institute for Global Health, Hyderabad, India

\section{Correspondence to} Dr Soumyadeep Bhaumik; sbhaumik@georgeinstitute. org.in

\section{ABSTRACT}

Introduction Snakebite is a neglected tropical disease. Snakebite causes at least 120000 death each year and it is estimated that there are three times as many amputations. Snakebite survivors are known to suffer from long-term physical and psychological sequelae, but not much is known on the mental health manifestations postsnakebite.

Methods We conducted a scoping review and searched five major electronic databases (Ovid MEDLINE(R), Global Health, APA PsycINF0, EMBASE classic+EMBASE, Cochrane Central Register of Controlled Trials), contacted experts and conducted reference screening to identify primary studies on mental health manifestations after snakebite envenomation. Two reviewers independently conducted titles and abstract screening as well as full-text evaluation for final inclusion decision. Disagreements were resolved by consensus. We extracted data as per a standardised form and conducted narrative synthesis.

Results We retrieved 334 studies and finally included 11 studies that met our eligibility criteria. Of the 11 studies reported, post-traumatic stress disorder (PTSD) was the most commonly studied mental health condition after snakebite, with five studies reporting it. Estimate of the burden of PTSD after snakebite was available from a modelling study. The other mental health conditions reported were focused around depression, psychosocial impairment of survivors after a snakebite envenomation, hysteria, delusional disorders and acute stress disorders. Conclusion There is a need for more research on understanding the neglected aspect of psychological morbidity of snakebite envenomation, particularly in countries with high burden. From the limited evidence available, depression and PTSD are major mental health manifestations in snakebite survivors.

\section{BACKGROUND}

Snakebite is a neglected tropical disease (NTD), with an estimated 4-18 million people being bitten, up to 120000 deaths and around three times as many amputations and other permanent disabilities caused globally every year. ${ }^{1-4}$ Most of the burden of snakebite is concentrated in rural and tribal(indigenous) communities of South Asia, Africa and Latin America. ${ }^{5}$ Snakebite has garnered increased attention in the last few years with
Key questions

What is already known?

- Snakebite is a neglected tropical disease which causes death and disability, particularly in rural and tribal people in South Asia, Africa and Latin America.

- Snakebite survivors are known to suffer from longterm physical and psychological sequala, but not much is known about mental health manifestations of snakebite.

What are the new findings?

- The study, to the best of our knowledge, is the first evidence synthesis on the topic. Only 11 studies (four case reports, one modelling, two cohort, two crosssection, one case-control and one randomised controlled trial) on mental health manifestations of snakebite were found.

- A high prevalence of post-traumatic stress disorder (PTSD) and depression was found in snakebite survivors. Other conditions like hysteria, and delusiona disorders were also reported.

- There is only one intervention study to address psychiatric morbidity after snakebite envenomation.

What do the new findings imply?

- There is a need for more research on psychiatric morbidity of snakebite, particularly in countries with high burden on priority basis. This will also help understand the true burden of snakebite.

- Depression and PTSD are major mental health manifestations in snakebite survivors. There is scarcity of mental health professionals in countries with high snakebite burden means there is need for research to understand how this can be dealt with in these health systems.

the World Health Assembly passing a resolution to address it in 2018, followed by a strategy to decrease the death and disability due to snakebite to $50 \%$ of current levels by $2030 .^{26}$

Snakebite survivors often suffer permanent or long-term physical and psychological consequences owing to myotoxicity, renal damage, neurotoxicity, coagulopathy and psychiatric manifestations-all of them not well studied. ${ }^{367}$ This is like many other 
NTDs where the focus has been rather concentrated on acute manifestation with chronic care and psychological manifestations ignored. ${ }^{8}{ }^{9}$ Since health comprises of both mental and physical aspects; addressing psychological and physical manifestations need to go hand in hand to provide an opportunity to snakebite survivors, and to create a positive change, enabling them to lead normal, happy and productive lives. ${ }^{10}$ Not only are the direct impacts of NTD-related disability on the individual still neglected in existing programmes, the indirect, yet significant, impacts on caregivers, families and communities are often completely overlooked.

While there are several systematic reviews on mental health for different NTDs, there is no evidence synthesis to understand mental health manifestations of snakebite. ${ }^{89}$ We, thus, undertook a broad scoping review to understand the current status of evidence for mental health conditions after snakebite globally.

\section{METHODOLOGY}

\section{Approach to the study}

We conducted a scoping review with the objective to understand available evidence on mental health conditions after a snakebite. A scoping review is more appropriate than a systematic review since the intention is to explore the breadth of evidence in the said broad topic area rather than answering a more focused specific question. We are reporting the study as per the Preferred Reporting Items for Systematic Reviews and Meta-Analyses Scoping Reviews (PRISMA-ScR) reporting guidelines and this checklist is provided in online supplemental material 1). An a priori protocol was developed but was not registered. Differences between protocol and conduct of scoping review is noted subsequently.

\section{Eligibility criteria}

Types of participants and condition of interest

We included studies that had persons with mental health conditions following a snakebite irrespective of presence of envenomation. Considering the broad scope of the review all mental health conditions that might be potentially related to snakebite was considered as conditions of interest. This included but was not be limited to:

1. Mood disorders (mania, depression).

2. Neurotic, stress-related and somatoform disorders (anxiety disorders, post-traumatic stress disorder (PTSD), somatic symptom disorders).

3. Behavioural syndromes associated with physiological disturbances and physical factors. Interaction of mental health conditions with other physical sequelae after snakebite and studies on interventions to address mental health on snakebite survivors.

Studies focusing only on physical sequelae of snakebite survivors with only hypothesised link to mental health were excluded.
Context

We included studies irrespective of the setting (acute care, primary care or the community), geographical location or cultural context in which the study was conducted.

Types of studies

We included primary studies of the following study design—qualitative studies, randomised controlled trial, non-randomised intervention studies, cohort studies, case-control, cross-sectional studies and individual case reports. We also included modelling studies.

Studies which did not have primary data to supplement mental health conditions after a snakebite envenomation and did not specifically answer the research question was excluded from the review.

\section{Information sources}

\section{Electronic databases}

We searched five electronic databases including a specialty mental health database to identify literature on 10 April 2020 without any restriction of language or dates. These are

- Ovid MEDLINE(R).

- Global Health.

- APA PsycINFO.

- Embase Classic+Embase.

- EBM Reviews-Cochrane Central Register of Controlled Trials.

Detailed search strategy is available in online supplemental material 2.

\section{Searching other resources}

We contacted experts in the domain of snakebite (through personal communication) and searched the reference lists of all included to identify additional studies.

\section{Selection of sources of evidence}

Two review authors independently screened records for consideration of inclusion based on title and/or abstracts. If decisions about inclusion were unclear at that stage, full texts of the citation were acquired and assessed for eligibility in the next phase of screening. In the next phase, at least two authors assessed full texts independently. Any disagreement about final eligibility was resolved by consensus with a third review author acting as an arbiter.

\section{Data charting process and content analysis}

Two review authors independently extracted data using a standardised data extraction form in Microsoft Excel. The data extraction form had two versions-one for individual case reports and the other for other study designs.

\section{Critical appraisal of individual studies}

We did not conduct risk of bias assessment of included studies as the study did not intend to understand the effect of quality of studies on study results. 


\section{Synthesis of results}

We grouped together studies on same or similar mental health conditions after snakebite envenomation and summarise the findings to identify areas where findings coalesce and where noteworthy gaps in evidence is observed. We did not conduct any additional quantitative analysis, other than what was reported in the study.

\section{Differences between protocol and systematic review}

We had initially planned to exclude modelling studies but considering the paucity of evidence we included modelling studies. Such post hoc change in criteria was possible because our search strategy was broad with no filters to remove any study designs. We added the modelling study, although it did not provide any primary data, owing to the general lack of data on the subject and to enhance the usability of the scoping review as a single-synthesised source of all evidence on a topic.

\section{Patient and public involvement}

Patients or public were not involved in any aspect of the study.

\section{RESULTS}

\section{Study selection}

We retrieved 328 records from retrieval of electronic databases and identified six additional records by other search methods. We assessed 27 full texts and finally included 11 publications. ${ }^{11-21}$ Reasons for 16 articles excluded at full text is presented in online supplemental material 3. The PRISMA flow chart showing study selection is shown in figure 1.

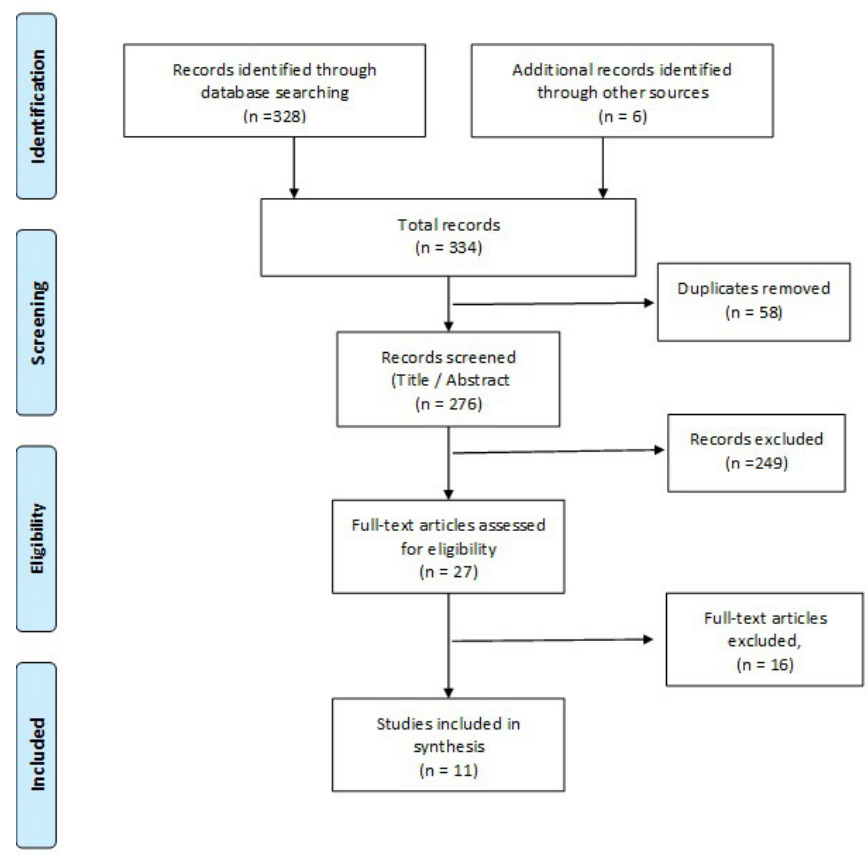

Figure 1 PRISMA flow chart showing selection of studies. PRISMA, Preferred Reporting Items for Systematic Reviews and Meta-Analyses.

\section{Characteristics of included studies}

We found four case reports (from Nigeria, ${ }^{12}$ Bangladesh, ${ }^{11} \operatorname{Iran}^{14}$ and India ${ }^{13}$ ), one modelling study, ${ }^{20}$ two cohort studies (from Iran ${ }^{17}$ and Nigeria ${ }^{21}$ ), two hospitalbased cross-sectional studies (from Nigeria ${ }^{18}$ and Bangladesh $^{19}$ ), one case-control study (with focus group component) from Sri Lanka ${ }^{16}$, and one randomised controlled trial from Sri Lanka. ${ }^{15}$ Only three studies ${ }^{17} 1921$ included those with snakebite, irrespective of envenomation status. All remaining studies had exclusively included those with snakebite envenomation only. Out of the three studies which included participants irrespective of envenomation status, two of them had more than $90 \%$ participants who had received snake anti-venom ${ }^{17} 21$ and one had $37.4 \%$ receiving antivenom. ${ }^{19}$

We found that PTSD was the most commonly studied mental health condition after snakebite, with five studies reporting it. Estimates of the burden of PTSD for snakebite envenomation was available from a modelling study. ${ }^{20}$ Other studies from Iran, ${ }^{17}$ Nigeria, ${ }^{21}$ Bangladesh ${ }^{19}$ and Sri Lanka ${ }^{16}$ focused on PTSD after snakebite envenomation. Depression was seen to be a focus of investigation in three studies. ${ }^{16} 1819$ One study focused on psychosocial impairment in snakebite envenomation survivors. ${ }^{21}$ Two case reports focused on hysteria (classified in International Statistical Classification of Diseases and Related Health Problems, 10th revision i.e. ICD-10 as unspecified Dissociative and conversion disorder), ${ }^{11} 12$ and one case report pertained to organic delusional (schizophrenialike) disorder ${ }^{13}$ after snakebite envenomation. Studies also focused on acute stress disorder ${ }^{17}$ and psychiatric symptoms like visual hallucinations, and anxiety. ${ }^{14} 19$ The randomised controlled trial from Sri Lanka ${ }^{15}$ aimed to assess the effectiveness of brief intervention on psychological morbidity due to snakebite (consisting of psychiatric symptoms, depression, psycho social disability, PTSD). This was the only interventional study. Most studies did not report funding. Two studies were funded by South Asian Clinical Toxicology Research Collaboration ${ }^{15} 16$ and one study by the Nigerian Field Epidemiology and Laboratory Training Program. ${ }^{18}$

Summary characteristics of included studies are presented in table 1 .

The results of the scoping review are presented into two broad subsections. The first provides a summary of evidence on several mental health conditions after snakebite envenomation and the later provides evidence on interventions to addressing it.

\section{Findings of mental health conditions after snakebite envenomation}

Post-traumatic stress disorder

Estimates of the proportion of snakebite survivors having PTSD varied from $8 \%$ to $43 \%$ across different studies reported in this review.

In Iran, PTSD was found in $8 \%$ of survivors with half of these developing chronic PTSD (statistically higher in younger people and also in females). ${ }^{17}$ The study 
Table 1 Characteristics of included studies

\begin{tabular}{|c|c|c|c|c|c|c|}
\hline $\begin{array}{l}\text { Author(s) } \\
\text { and year of } \\
\text { publication }\end{array}$ & Study design & Country & Study setting & Funding & $\begin{array}{l}\text { Conflict of } \\
\text { interest }\end{array}$ & $\begin{array}{l}\text { Mental health condition } \\
\text { reported after snakebite } \\
\text { (including envenomation } \\
\text { status) }\end{array}$ \\
\hline \multicolumn{7}{|c|}{ CASE REPORTS } \\
\hline Ali $1948^{11}$ & Case report & Bangladesh & $\begin{array}{l}\text { 40-year-old woman } \\
\text { seen in community } \\
\text { (home-visit) in a rural } \\
\text { area }\end{array}$ & Not reported & Not reported & $\begin{array}{l}\text { Hysteria (non-convulsive) } \\
\text { after snakebite envenoming }\end{array}$ \\
\hline $\begin{array}{l}\text { Adogu et al, } \\
1992^{12}\end{array}$ & Case report & Nigeria & $\begin{array}{l}\text { 17-year-old woman } \\
\text { admitted in emergency } \\
\text { department of a } \\
\text { hospital }\end{array}$ & Not reported & Not reported & $\begin{array}{l}\text { Hysterical paralysis of } \\
\text { limb after snakebite } \\
\text { (unidentified) envenoming }\end{array}$ \\
\hline $\begin{array}{l}\text { Mehrpour et } \\
\text { al } 2018^{14}\end{array}$ & Case report & Iran & $\begin{array}{l}\text { 19-year-old man soldier } \\
\text { admitted in emergency } \\
\text { department of a } \\
\text { hospital }\end{array}$ & Not reported & $\begin{array}{l}\text { Authors } \\
\text { declared no } \\
\text { competing } \\
\text { interests. }\end{array}$ & $\begin{array}{l}\text { Visual hallucination } \\
\text { (psychiatric symptom only } \\
\text { with no cause identified) } \\
\text { after Adder envenoming }\end{array}$ \\
\hline $\begin{array}{l}\text { Ratnakaran } \\
\text { et al, } 2016^{13}\end{array}$ & Case report & India & $\begin{array}{l}\text { 42-year-old man } \\
\text { who attended skin } \\
\text { outpatient department } \\
\text { initially }\end{array}$ & No funding & $\begin{array}{l}\text { Authors } \\
\text { declared no } \\
\text { competing } \\
\text { interests. }\end{array}$ & $\begin{array}{l}\text { Organic delusional } \\
\text { (schizophrenia-like) disorder } \\
\text { (ICD-10). psychosis in clear } \\
\text { consciousness following } \\
\text { a secondary empty Sella } \\
\text { syndrome as the sequelae } \\
\text { of a Russel's Viper } \\
\text { envenoming }\end{array}$ \\
\hline
\end{tabular}

\section{OTHER PRIMARY STUDIES}

\begin{tabular}{|c|c|c|c|c|c|c|}
\hline $\begin{array}{l}\text { Williams et } \\
\text { al, } 2011^{16}\end{array}$ & Case-control & Sri Lanka & $\begin{array}{l}\text { Rural area with } \\
\text { predominantly } \\
\text { agricultural population } \\
\text { in an area with high } \\
\text { snakebites }\end{array}$ & $\begin{array}{l}\text { South Asian } \\
\text { Clinical } \\
\text { Toxicology } \\
\text { Research } \\
\text { Collaboration }\end{array}$ & $\begin{array}{l}\text { Authors } \\
\text { declared no } \\
\text { competing } \\
\text { interests. }\end{array}$ & $\begin{array}{l}\text { Depression; PTSD after } \\
\text { snakebite envenoming }\end{array}$ \\
\hline $\begin{array}{l}\text { Khosrojerdi } \\
\text { and Amini, } \\
2013^{17}\end{array}$ & Cohort & Iran & $\begin{array}{l}\text { Hospital based in a } \\
\text { medical toxicology } \\
\text { centre }\end{array}$ & No funding & $\begin{array}{l}\text { Authors } \\
\text { declared no } \\
\text { competing } \\
\text { interests. }\end{array}$ & $\begin{array}{l}\text { Acute stress disorder; } \\
\text { PTSD after snakebite, } \\
\text { irrespective of } \\
\text { envenomation status } \\
\text { (90.5\% received snake } \\
\text { anti-venom) }\end{array}$ \\
\hline $\begin{array}{l}\text { Wijesinghe } \\
\text { et al, } 2015^{15}\end{array}$ & $\begin{array}{l}\text { Randomised } \\
\text { Controlled } \\
\text { Trial }\end{array}$ & Sri Lanka & $\begin{array}{l}\text { Predominantly rural } \\
\text { agricultural population } \\
\text { in an area with highest } \\
\text { numbers of reported } \\
\text { snakebites }\end{array}$ & $\begin{array}{l}\text { South Asian } \\
\text { Clinical } \\
\text { Toxicology } \\
\text { Research } \\
\text { Collaboration }\end{array}$ & $\begin{array}{l}\text { Authors } \\
\text { declared no } \\
\text { competing } \\
\text { interests. }\end{array}$ & $\begin{array}{l}\text { Depression; Psychosocial } \\
\text { disability; PTSD after } \\
\text { snakebite envenoming }\end{array}$ \\
\hline $\begin{array}{l}\text { Muhammed } \\
\text { et al, } 2017^{18}\end{array}$ & $\begin{array}{l}\text { Cross- } \\
\text { sectional }\end{array}$ & Nigeria & $\begin{array}{l}\text { Regional snakebite } \\
\text { reference centre in } \\
\text { a hospital within the } \\
\text { Sudan savannah } \\
\text { vegetation of the Benue } \\
\text { river valley and known } \\
\text { for carpet vipers' } \\
\text { envenomation. }\end{array}$ & $\begin{array}{l}\text { Nigerian Field } \\
\text { Epidemiology } \\
\text { and } \\
\text { Laboratory } \\
\text { Training } \\
\text { Programme }\end{array}$ & $\begin{array}{l}\text { Authors } \\
\text { declared no } \\
\text { competing } \\
\text { interests. }\end{array}$ & $\begin{array}{l}\text { Depression after snakebite } \\
\text { envenoming (inferred as all } \\
\text { patients had received anti- } \\
\text { venom) }\end{array}$ \\
\hline $\begin{array}{l}\text { Rahman et } \\
\text { al, 2018 }\end{array}$ & $\begin{array}{l}\text { Cross- } \\
\text { sectional }\end{array}$ & Bangladesh & $\begin{array}{l}\text { Hilly area with } \\
\text { predominantly tribal } \\
\text { population }\end{array}$ & $\begin{array}{l}\text { Not } \\
\text { mentioned }\end{array}$ & Not reported & $\begin{array}{l}\text { Psychiatric manifestations } \\
\text { (in general); PTSD; } \\
\text { Depression after } \\
\text { snakebite, irrespective } \\
\text { of envenomation status } \\
\text { (34.7\% received snake } \\
\text { anti-venom) }\end{array}$ \\
\hline
\end{tabular}




\begin{tabular}{|c|c|c|c|c|c|c|}
\hline $\begin{array}{l}\text { Author(s) } \\
\text { and year of } \\
\text { publication }\end{array}$ & Study design & Country & Study setting & Funding & $\begin{array}{l}\text { Conflict of } \\
\text { interest }\end{array}$ & $\begin{array}{l}\text { reported after snakebite } \\
\text { (including envenomation } \\
\text { status) }\end{array}$ \\
\hline $\begin{array}{l}\text { Habib et al, } \\
2020^{21}\end{array}$ & Cohort & Nigeria & $\begin{array}{l}\text { General Hospital in } \\
\text { an insurgency prone } \\
\text { area. The hospital is } \\
\text { in a semi-urban town } \\
\text { that serves as the } \\
\text { headquarters to the } \\
\text { Local Government } \\
\text { Area. }\end{array}$ & Not reported & $\begin{array}{l}\text { Authors } \\
\text { declared no } \\
\text { competing } \\
\text { interests. }\end{array}$ & $\begin{array}{l}\text { Psychosocial impairment, } \\
\text { PTSD after snakebite, } \\
\text { irrespective of } \\
\text { envenomation status ( } 93 \% \\
\text { received snake antivenom) }\end{array}$ \\
\hline \multicolumn{7}{|c|}{ MODELLING STUDY } \\
\hline $\begin{array}{l}\text { Halilu et al, } \\
2019^{20}\end{array}$ & Modelling & $\begin{array}{l}41 \text { sub- } \\
\text { Saharan } \\
\text { African } \\
\text { countries }\end{array}$ & $\begin{array}{l}41 \text { sub-Saharan African } \\
\text { countries }\end{array}$ & Not reported & Not reported & $\begin{array}{l}\text { PTSD after snakebite } \\
\text { envenoming }\end{array}$ \\
\hline
\end{tabular}

PTSD, post-traumatic stress disorder.

used the Structured Clinical Interview for DSM-IV Axis I Disorder (SCID-1) questionnaire for diagnosis. The study from Sri Lanka ${ }^{16}$ found that the mean Post-traumatic Stress Symptom Scale-Self Report score among snakebite envenoming cases was 10.5 (SD 12.7) with $21.6 \%$ of cases meeting the criteria of PTSD. The total PTSD score was also seen to correlate strongly with the disability scores and the depression and anxiety scores in the study. This was similar to what was reported in a study among tribal population in Bangladesh having a prevalence of $27.3 \%$ for PTSD. ${ }^{19}$ The prevalence of PTSD among those exposed to snakebite was reported to be even higher at $43 \%$ in the study from Nigeria. ${ }^{21}$

Halilu et $a l^{20}$ in their modelling study, estimated a total of 55332 (95\% CI 45826 to 64769 ) PTSD cases after snakebite envenomation (among 268471 snakebite cases) in 41 sub-Saharan countries. Overall PTSD was estimated to account for $14.9 \%$ of the total burden after snakebite envenomation. With a PTSD disability weight of 0.11 being applied, the estimated burden of PTSD after snakebite envenomation was estimated to be 0.88 million disability-adjusted life years (DALYs) $(95 \%$ CI 0.68 to 1.11 million DALYs) and 0.91 million DALYs (95\% CI 0.70 to 1.14 million DALYs) for scenarios of $4 \%$ and $21.6 \%$ of survivors developing chronic untreated PTSD, respectively. The study also provides country level estimates for the same. However, a key limitation of the study was that the study used prevalence of PTSD in snakebite envenoming $(21.6 \%)$ observed in a study from Sri Lanka (reported later) rather from within Africa and the average duration used was for PTSD in general and not specifically after snakebite envenoming in the modelling exercise.

\section{Depression}

The prevalence of depression in those affected by snakebite ranged from $25 \%$ to $54 \%$ in different studies.
The lowest prevalence was reported in a study from Nigeria ${ }^{18}$ where $25 \%$ of patients had a diagnosis of depression (with $7.5 \%$ being moderate and 4.35 being severe), detected through the Patient Health Questionnaire but with none of the cases were recognised by attending clinicians. Severe depression was found to be significantly associated with history of snakebites (OR 8.3, 95\% CI 1.9 to 36.5 ), worrying about financial loss (OR 14.6, 95\% CI 1.8 to 121.5 ), time loss (OR $14.6,95 \%$ CI 1.8 to 121.5 ) and family welfare (OR $31.5,95 \%$ CI 6.5 to 152.9 ).

The prevalence of depression was much higher at $33.9 \%$ in the study among tribal people of the hilly tracts of Bangladesh. ${ }^{19}$ The study from Sri Lanka ${ }^{16}$ found that mean depression score was 19.1 (SD 7.7) in snakebite cases (using the Modified Sinhala version of the Beck depression inventory) which was significantly higher than that of controls who had a score of 14.4 (SD 2.5)) (p,0.001; mean difference 4.74 (95\% CI 3.02 to 6.46$)$ ). This translated to $54 \%$ of those who were affected by snakebite having depression (compared with $15 \%$ in controls). The value was much lower at $23 \%$ of cases (compared with $2.3 \%$ of controls) having depression when using the depression subscale scores in the Hopkins checklist.

Hysteria (currently classified in ICD-10 as unspecified Dissociative and conversion disorder)

There are two case reports on hysteria after snakebiteone from Bangladesh in $1948^{11}$ and another from Nigeria in 1992. ${ }^{12}$ Both these cases were females and were manifested in the acute setting with no long-term sequelae reported. There are no other studies reported.

Organic delusional (schizophrenia-like) disorder

There is only one reported case of organic delusional (schizophrenia-like) disorder (ICD-10) from India published in $2018 .^{13}$ The patient was a 42 -year-old man who initially presented with symptoms of 'generalised 
hypopigmentation of the skin and truncal hair loss, which was gradual in onset of more than 12 years' after a Russel viper bite (based on history). The diagnosis was done by specialist psychiatrist with the condition manifesting as 'psychosis in clear consciousness following a secondary empty Sella syndrome as the sequelae of a snake bite'. ${ }^{13}$

\section{Psychosocial impairment}

There was only one study from Nigeria on psychosocial impairment in survivors of snakebite and it found that survivors had significantly poorer quality of life score in the psychological and social domains using the Brief version of the WHO Quality of Life Instrument. ${ }^{21}$ Those with snakebite also had impaired family/school functioning (using Sheehan's Disability Scale).

\section{Other unspecified mental health manifestations}

A study from $\operatorname{Iran}^{17}$ reported an acute stress disorder in $15 \%$ of patients with snakebite (3 weeks postbite) using the SCID1 questionnaire. Acute stress disorder was significantly higher in those who were younger and female.

A study from Bangladesh ${ }^{19}$ reported acute (early) psychiatric manifestations like 'hallucination (25.6\%), acute psychosis (15.7\%), psychogenic convulsion $(2.4 \%)$, difficulty in concentration $(2.4 \%)$ and aggressive behaviour $(0.8 \%)^{\prime}$ without any specific psychiatric diagnosis. Transient visual hallucination, with no chronic sequelae also noted in a case of a 19-year-old man soldier who had been bitten by an Adder snake. ${ }^{14}$

\section{Intervention to prevent mental health condition after snakebite envenoming}

There was only one intervention study-a randomised controlled trial conducted in Sri Lanka ${ }^{15}$ which evaluated the effectiveness of the following interventions, administered by non-specialist doctors, who had been trained by a specialist psychiatrist, for preventing psychological morbidity after snakebite envenoming:

- Psychological first aid and psychoeducation at discharge.

- Cognitive-behavioural therapy (CBT) intervention (single brief session conducted 1 month post-discharge).

Both the arms were compared with a control arm which did not receive any intervention. The study ${ }^{15}$ found that none of the two interventions were effective in decreasing the proportion of patients diagnosed with depression or PTSD. The study reported only a trend for decrease in psychiatric symptoms of depression from no intervention to those who received intervention at discharge and those who received CBT 1-month postdischarge $\left(\chi^{2}\right.$ test for trend $=7.901, \mathrm{p}=0.005)$. A similar trend was also noted for overall prevalence of disability $\left(\chi^{2}\right.$ for trend $=7.551$, $\mathrm{p}=0.006)$.

\section{DISCUSSION}

Our scoping review found only 11 studies globally, which included four case reports and one modelling study, on mental health after snakebite-thus demonstrating the scarcity of evidence on it. From available evidence, PTSD and depression are seen to be important mental health conditions after snakebite envenomation, with estimates of its prevalence, as high as $43 \%$ and $53 \%$. Studies have reported anxiety as a manifestation too. Not much is known about other mental health conditions in snakebite survivors. There was only one interventional study - a randomised controlled trial which found nonspecialist doctor delivered interventions were not effective in preventing depression or PTSD.

The prevalence of depression and PTSD after snakebite envenomation varied widely between studies and might be due to the setting, the type and nature of snakebite experienced or the screening tool used to identify the mental health conditions (no single screening tool was used across studies to enable comparison). Only three studies had included participants irrespective of envenoming status-with majority of them being on those envenomed. Based on current evidence, it is thus not possible to say how common mental health condition is after bites due to non-venomous snakes or due to bites by venomous snakes with no clinical symptoms (i.e. dry bites). Species-specific information is also not available. There are several socioeconomic and cultural factors that are associated with snakebite which include losses associated with premature death and ill health sequelae, loss of productivity and ability to work, and healthcare expenses associated with human cases in affected households. ${ }^{22}{ }^{23}$ Screening tools for mental health conditions are important in the context of snakebite, as its burden is majorly in low-income and-middle-income countries (LMICs) and in primary care setting, where specialist psychiatric services are almost non-existent, an issue well recognised in mental health literature. ${ }^{24-26}$ The General Health Questionnaire-12 has been validated in multiple settings for common mental health disorders for those with physical illness ${ }^{25}$ - and this might be the most suitable for the purpose of mental health after snakebite envenoming. For PTSD particularly, the Harvard Trauma Questionnaire and Post-traumatic Diagnostic Scale are the most commonly validated tool in LMIC setting. ${ }^{24}$ This apart there are other tools like Primary Care PTSD screen-5 which leads to those being screened positive undergoing specialist psychiatric assessment or through a more detailed Clinician-Administered PTSD Scale for Diagnostic and Statistical Manual of Mental Disorders (DSM), 5th revision (CAPS-5) ${ }^{27}{ }^{28}$ However, these tools have not been evaluated for in countries with high snakebite burden(like India, sub-Saharan African and Latin American countries). ${ }^{24}$ The validation of tools in multiple countries important considering the cultural and religious connotations around snakebite in almost all countries. ${ }^{529-31}$ such, there is a requirement of validating even tools in the context of snakebite in different settings using the diagnostic interviews by specialist mental health professionals which can take into account cross-cultural issues. ${ }^{32}$ In addition to this, 
it is also important to conduct studies which look at the mechanisms of the stress/trauma that has been caused due to snake bite envenomation such that interventions can be designed to address the psychological morbidity of snakebite accordingly. Exploring the links between socio-cultural and religious contexts, including stigma and mental health manifestations is key-there is need for more social sciences research in this domain. ${ }^{7}$ Role of gender and diagnosis of PTSD has been mentioned by Khosrojerdi and Amini ${ }^{17}$ but gender issues largely remains underexplored. Understanding the effect of snakebite envenomation on individuals with pre-existing mental health conditions and those who are at high risk for developing mental disorders, for example, refugees is required.

Overall there is a need for funders as well as researchers to study mental health after snakebite envenomation globally. Our scoping review found almost no evidence from countries which have high burden of snakebite, including from India. While it is known that India contributes to about half of the global deaths due to snakebite, the lack of evidence around the burden due to mental health conditions like PTSD and depression needs priority attention. In October 2020, WHO has released an advocacy brief on mental health of people with NTDs which calls for people-centric integrated care to address it. ${ }^{33}$ The list of practical guidelines and manuals provided in the advocacy brief ${ }^{33}$ does not have any specific advice for snakebite, and all the evidence and case- studies cited are from other NTD, although snakebite is mentioned. Snakebite is the only non-communicable disease classified as an NTD, and as such, evidence for other NTDs might not be transferable to snakebite. The WHO-SEARO guidelines and the WHO-AFRO guidelines on snakebite also do not provide any specific advice on aspects of management. ${ }^{34}{ }^{35}$ There is a need for developing specific guidance on the topic while the evidence base for the same is developed.

The scarcity of mental health professionals in countries with high snakebite burden means there is need for research on modality of implementation of interventions (particularly type of health workforce engaged) which can address the problem. ${ }^{36}{ }^{37}$ Interventions to improve recognition of mental health manifestations of snakebite by primary care clinicians is essential. There is also need for primary research to understand the natural history of mental health manifestations and its social and cultural aspects. Research on mental health conditions after snakebite envenomation will not only help understanding clinical management (thus contributing to development of integrated care models for snakebite envenomation ${ }^{6}$ but will also help understand the true disease burden of snakebite. Snakebite like many others NTDs have lowest disability burdens being assigned to them owing to lack of recognition of the chronic aspects, ${ }^{9}$ particularly mental health manifestations, of the condition. This can not only help us understand morbidity and aspects of clinical management better, it can also provide us information on the economic costs of the disease and the burden on caregivers.

\section{CONCLUSION}

Depression and PTSD are major causes of morbidity in those with snakebite envenomation but remain understudied and underexplored globally. There is a need for more research on understanding the neglected aspect of morbidity of snakebite, particularly in countries with high burden.

Twitter Soumyadeep Bhaumik @DrSoumyadeepB

Acknowledgements SB is supported by the University International Postgraduate Award (UIPA) by University of New South Wales (UNSW), Sydney, Australia.

Contributors Conceptualisation: SB. Data curation: All authors. Formal analysis: SB, SK. Methodology: SB. Project administration: SB, SK. Validation: SK, AK, MD, SD. Writing —original draft: SB, SK. Writing—review and editing: All authors guarantor(s): all authors.

Funding The authors have not declared a specific grant for this research from any funding agency in the public, commercial or not-for-profit sectors.

Competing interests None declared.

Patient consent for publication Not required.

Provenance and peer review Not commissioned; externally peer reviewed.

Data availability statement All data relevant to the study are included in the article or uploaded as online supplemental information.

Supplemental material This content has been supplied by the author(s). It has not been vetted by BMJ Publishing Group Limited (BMJ) and may not have been peer-reviewed. Any opinions or recommendations discussed are solely those of the author(s) and are not endorsed by BMJ. BMJ disclaims all liability and responsibility arising from any reliance placed on the content. Where the content includes any translated material, BMJ does not warrant the accuracy and reliability of the translations (including but not limited to local regulations, clinical guidelines, terminology, drug names and drug dosages), and is not responsible for any error and/or omissions arising from translation and adaptation or otherwise.

Open access This is an open access article distributed in accordance with the Creative Commons Attribution Non Commercial (CC BY-NC 4.0) license, which permits others to distribute, remix, adapt, build upon this work non-commercially, and license their derivative works on different terms, provided the original work is properly cited, appropriate credit is given, any changes made indicated, and the use is non-commercial. See: http://creativecommons.org/licenses/by-nc/4.0/.

\section{ORCID iD}

Soumyadeep Bhaumik http://orcid.org/0000-0001-9579-4453

\section{REFERENCES}

1 Kasturiratne A, Wickremasinghe AR, de Silva N, et al. The global burden of snakebite: a literature analysis and modelling based on regional estimates of envenoming and deaths. PLoS Med 2008;5:e218.

2 Sachan D. The snake in the room: snakebite's huge death toll demands a global response. BMJ 2018;361:k2449.

3 Harrison RA, Gutiérrez JM. Priority actions and progress to substantially and Sustainably reduce the mortality, morbidity and socioeconomic burden of tropical snakebite. Toxins 2016;8. doi:10.3390/toxins8120351. [Epub ahead of print: 2411 2016].

4 Gutiérrez JM, Warrell DA, Williams DJ, et al. The need for full integration of snakebite envenoming within a global strategy to combat the neglected tropical diseases: the way forward. PLoS Negl Trop Dis 2013;7:e2162 https://dx.doi.org/

5 Bhaumik S. Snakebite: a forgotten problem. BMJ 2013;346:f628.

6 WHO. Snakebite envenoming - A strategy for prevention and control. Geneva: World Health Organisation, 2019.

7 Gutiérrez JM, Burnouf T, Harrison RA, et al. A call for incorporating social research in the global struggle against snakebite. PLoS Negl Trop Dis 2015;9:e0003960. 
8 Kuper H. Neglected tropical diseases and disability-what is the link? Trans R Soc Trop Med Hyg 2019;113:839-44.

9 Bailey F, Eaton J, Jidda M, et al. Neglected tropical diseases and mental health: progress, partnerships, and integration. Trends Parasitol 2019;35:23-31.

10 Hamill LC, Haslam D, Abrahamsson S, et al. People are neglected, not diseases: the relationship between disability and neglected tropical diseases. Trans R Soc Trop Med Hyg 2019;113:829-34.

11 Ali M. An interesting case of hysterical manifestations due to snake bite. Antiseptic 1948;45:640.

12 Adogu AA, Abbas M, Ishaku D. Hysterical paralysis as a complication of snake bite. Trop Geogr Med 1992;44:167-9.

13 Ratnakaran B, Punnoose VP, Das S, et al. Psychosis in secondary empty sella syndrome following a Russell's viper bite. Indian $\mathrm{J}$ Psychol Med 2016;38:254-6.

14 Mehrpour O A, Akbari NS, et al. A case report of a patient with visual hallucinations following snakebite. J Surg Trauma 2018;6:73-6.

15 Wijesinghe CA, Williams SS, Kasturiratne A, et al. A randomized controlled trial of a brief intervention for delayed psychological effects in snakebite victims. PLoS Negl Trop Dis 2015;9:e0003989.

16 Williams SS, Wijesinghe CA, Jayamanne SF, et al. Delayed psychological morbidity associated with snakebite envenoming. PLoS Negl Trop Dis 2011;5:e1255.

17 Khosrojerdi H, Amini M. Acute and delayed stress symptoms following snakebite. Asia Pac J Med Toxicol 2013;2:140-4.

18 Muhammed A, Dalhat MM, Joseph BO, et al. Predictors of depression among patients receiving treatment for snakebite in general Hospital, Kaltungo, Gombe state, Nigeria: August 2015. Int J Ment Health Syst 2017;11:26.

19 Rahman M, Uddin MK, Sultana S, et al. Snake bites with neuropsychiatric presentation - a study in Hill tracts of Bangladesh. J Enam Med 2018;8:20-4.

20 Halilu S, Iliyasu G, Hamza M, et al. Snakebite burden in sub-Saharan Africa: estimates from 41 countries. Toxicon 2019;159:1-4.

21 Habib ZG, Salihu AS, Hamza M, et al. Posttraumatic stress disorder and psycho-social impairment following snakebite in northeastern Nigeria. Int J Psychiatry Med 2020:009121742091340.

22 Kasturiratne A, Pathmeswaran A, Wickremasinghe AR, et al. The socio-economic burden of snakebite in Sri Lanka. PLoS Negl Trop Dis 2017;11:e0005647.
23 Babo Martins S, Bolon I, Chappuis F, et al. Snakebite and its impact in rural communities: the need for a one health approach. PLoS Negl Trop Dis 2019;13:e0007608.

24 Mughal AY, Devadas J, Ardman E, et al. A systematic review of validated screening tools for anxiety disorders and PTSD in low to middle income countries. BMC Psychiatry 2020;20:338.

25 Ali G-C, Ryan G, De Silva MJ. Validated screening tools for common mental disorders in low and middle income countries: a systematic review. PLoS One 2016;11:e0156939.

26 Spoont M, Arbisi P, Fu S, et al. Screening for post-traumatic stress disorder (PTSD) in primary care: a systematic review. evidencebased synthesis program reports. Washington, DC: Department of Veterans Affairs (US), 2013.

27 Prins A, Ouimette P, Kimerling R, et al. The primary care PTSD screen (PC-PTSD): development and operating characteristics. Primary Care Psychiatry 2004;9:9-14.

28 Weathers FW, Bovin MJ, Lee DJ, et al. The Clinician-Administered PTSD scale for DSM-5 (CAPS-5): development and initial psychometric evaluation in military veterans. Psychol Assess 2018;30:383-95

29 Landová E, Bakhshaliyeva N, Janovcová M, et al. Association between fear and beauty evaluation of snakes: cross-cultural findings. Front Psychol 2018;9:333.

30 Williamson WP, Hood RW. Religious serpent handling and community relations. J Prev Interv Community 2015;43:186-98

31 Kumar A. Snakebite: sociocultural anthropological bias. PLoS Med 2006;3:e412.

32 Bolton P. Cross-Cultural validity and reliability testing of a standard psychiatric assessment instrument without a gold standard. J Nerv Ment Dis 2001;189:238-42.

33 World Health Organization. Mental health of people with neglected tropical diseases: towards a person-centred approach. Geneva: World Health Organization, 2020.

34 WHO-AFRO. Guidelines for the prevention and clinical management of snakebite in Africa. Mauritius; 2010.

35 WHO-SEARO. Guidelines for the management of snake-bites. 2nd ed. New Delhi, 2016.

36 Jacob KS. Repackaging mental health programs in low- and middleincome countries. Indian J Psychiatry 2011;53:195-8.

37 Bruckner TA, Scheffler RM, Shen G, et al. The mental health workforce gap in low- and middle-income countries: a needs-based approach. Bull World Health Organ 2011;89:184-94. 